\title{
Therapeutic Efficacy of Hydrochlorothiazide in the Primary Monosymptomatic Nocturnal Enuresis of Children
}

\author{
Parsa Yousefichaijan, ${ }^{1}$ Masoud Rezagholizamenjany, ${ }^{2}$ Fatemeh Dorreh, ${ }^{3}$ Hassan Taherahmadi, ${ }^{4}$ \\ Mohamad Rafiei, ${ }^{5}$ Sahar Aslani, ${ }^{2}$ and Ali Arjmand ${ }^{4}$ \\ ${ }^{1}$ Associate Professor of Pediatric Nephrology, Department of Pediatric Nephrology, Amir Kabir Hospital, Arak University of Medical Sciences, Arak, IR Iran \\ ${ }^{2}$ School of Medicine, Arak University of Medical Sciences, Arak, IR Iran \\ ${ }^{3}$ Department of Pediatric, Associate Professor of Pediatric, Arak University of Medical Sciences, Arak, IR Iran \\ ${ }^{4}$ Department of Pediatric, Assistant Professor of Pediatric, Arak University of Medical Sciences, Arak, IR Iran \\ ${ }^{5}$ Department of Biostatistics, Arak University of Medical Sciences, Arak, IR Iran \\ "Corresponding author: Masoud Rezagholizamenjany, Kerahrod Street, Arak, IR Iran. Tel: +98-9184374727; +98-8634573785, E-mail: masoudrezagholio74@gmail.com
}

Received 2017 May 11; Revised 2017 June 22; Accepted 2017 September 19.

\begin{abstract}
Background: Nocturnal enuresis is a symptom with probably multiple etiologic factors and a high prevalence. Conventional therapies is expensive and complicated, since the effect of calcium on voiding dysfunction was approved. Therefore, to the current study aimed at evaluating the therapeutic effect of hydrochlorothiazide on primary monosymptomatic nocturnal enuresis (PMNE).

Methods: The current study was conducted based on the interviews with patients. Morning urine test was evaluated in children with PMNE detection and specific gravity < 1010 enrolled to the study ( 110 children comprised of 57 cases and 53 controls). Children were divided into 2 groups; in the case group, hydrochlorothiazide (tablet $1 \mathrm{mg} / \mathrm{kg}$ and maximum $50 \mathrm{mg}$ ) was administered in the morning and the control group was only given necessary training about enuresis. For 3 times and with 1 month interval (based on a predetermined questionnaire) the frequency of nocturnal enuresis was checked. Data were transferred into SPSS program and the therapeutic effect of hydrochlorothiazide on primary monosymptomatic nocturnal enuresis was investigated.

Findings: There was a statistically significant difference regarding the frequency of nocturnal enuresis between the 2 groups $(\mathrm{P}=$ $0.0001)$. Also, both groups were matched by age $(P=899)$ and gender $(P=607)$.

Conclusions: Hydrochlorothiazide can be used as an effective and safe therapeutic option for treatment of primary monosymptomatic nocturnal enuresis.
\end{abstract}

Keywords: Nocturnal Enuresis, Treatment, Hydrochlorothiazide, Children

\section{Background}

Primary monosymptomatic nocturnal enuresis (PMNE), as a symptom means the involuntary urination at least 2 nights a month in children older than 5 years of age; this is despite the fact that most children gain voiding control at night from the age of 3 and these capabilities are earlier in females than males $(1,2)$. As a common childhood problem, it has a prevalence of $1.6 \%$ to $15 \% ; 10 \%$ in 6-year old, and 5\% in 14-year children still wet the bed at night $(3,4)$. Children who have never gained urination control (about 75\% of cases) are defined as primary $\mathrm{NE}$, and other children with development of incontinence at least in 6 months (25\% of cases) are the secondary NE $(5,6)$. Moreover, NE without daytime urinary symptoms is defined as monosymptomatic, and NE with daytime urinary symptoms is defined as nonmonosymptomatic $\mathrm{NE}$, which is accompanied by daytime urinary symptom (7). Idiopathic hypercalciuria (IHC) is a cause of urinary problems in children such as nephrolithiasis (6). Also, various manifestations of clinical urinary disorders such as recurrent abdominal pain, hematuria, urinary tract infections (UTIs), urgency, dysuria, and urinary incontinence are common in children with $\operatorname{IHC}(8,9)$. The influence of genetic factors hypothesized as another etiology of PMNE also identified as autosomal dominant patterns for it $(10,11)$. Since children with NE do not have a psychiatric disorder, control of bladder may be lost by a stressful life, also physiology of sleep condition may play a role in the etiology of NE, with a commonly noted high arousal threshold. Detrusor muscle malfunction with a tendency for involuntary contractions and small amounts of urine in bladder are considered as another possible etiology $(8,12)$. NE may be associated with reduction of bladder capacity commonly observed in children with chronic constipation that leads to large dilated of distal colon impinging on bladder as another etiology of $\mathrm{NE}(4,13,14)$.

According to a recent observation, there is a significant correlation between urination volume (polyuria) in night and excretion of calcium $(6,15,16)$. To treat this condition 
thiazide diuretics are used as drugs that are easy to use, have few complications, are inexpensive, widely available, and acceptable (17). Thiazides induce calcium reabsorption in distal tubules of kidney and ameliorate hypercalciuria (18-20). Based on the context, it was found that idiopathic hypercalciuria was a strong cause of NE, and hydrochlorothiazide (HCT) significantly improved hypercalciuria condition; therefore, it was suggested to evaluate the therapeutic effects of HCT on the improvement of NE condition. The current study considered the effect of HCT on the treatment of PMNE in children, males and females, in order to find a better treatment.

\section{Methods}

\subsection{Study Setting}

The current hospital-based study was conducted in the pediatric clinic of Amir-Kabir hospital.

\subsection{Study Population}

For our case-control study we randomly selected a representative sample from all male and female children over 5 years old with PMNE who referred to Amir Kabir hospital. The sample size was 110 children comprised 53 subjects in the control group and 57 patients in the case group. Observations and samples recruitment were performed based on the random permutation of the blocks.

\subsection{Measurements}

Both the case and control groups were matched by demographic characteristics and socioeconomic status. In the case group, HCT (tablet $1 \mathrm{mg} / \mathrm{kg}$ and maximum $50 \mathrm{mg}$ ) was prescribed in the morning; also, about NE subjects were given the necessary training. Subjects in the control group only received the necessary training about NE. For 3 months, according to a predetermined questionnaire and with 1-month intervals, the frequency of nocturnal enuresis was evaluated and 3 months later, the follow-up data were collected and analyzed by SPSS program.

\subsection{Ethical Considerations}

Ethical issues, including plagiarism, data fabrication, and double publication were completely observed by the authors. In addition, the Ethical Committee of Arak University of Medical Sciences, Arak, Iran, approved the protocol of the study (code number: 93-172-7).

\subsection{Statistical Analysis}

Data analysis was conducted by the chi-square and $t$ test with SPSS program and $\mathrm{P}<0.05$ was considered as statistically significant difference.

\subsection{Inclusion and Exclusion Criteria}

Children with 5 to 18 years of age and positive PMNE diagnosis based on Nelson book and pediatrics confirmation were assigned to the case group. Children with no mental and physical illnesses and a specific gravity lower than 1010 were enrolled. In addition, non-cooperation of parents and children, the presence of any chronic disease, and chronic use of any drugs were considered as exclusion criteria.

\subsection{Necessary Training}

- Drinking lots of liquid was recommended during the day to increase bladder capacity and decrease or stop liquid intake after 7:00 pm.

- Special diet: Avoidance irritating substances and carbonated drinks.

- Completely emptying the bladder at night, before bedtime.

- Gradually increasing the time between liquid intake and urination.

- Exercise

- Training toilet manners and encouraging the child for urinary voiding.

\section{Results}

Totally, out of the 57 patients with PMNE in the case group, 34 patients were male (7/59\%) and 23 patients were female (3/40\%), and out of the 53 patients in the control group 27 patients were male (9/50\%) and 26 patients were female $(1 / 49 \%)$; based on this about gender of children there was no significant differences between the groups ( $P$ $=0.359$ ). The mean age of children in the case and control groups were $8.35 \pm 1.94$ and $8.21 \pm 1.99$ years, respectively $(\mathrm{P}=0.802)$. In addition, the youngest child was 6 years old and the oldest one was 13 years old (Table 1). As shown in Table 1 , the age of children was not significantly different between the 2 groups $(\mathrm{P}=0.223)$.

Also, as shown in Table 2, the mean of episodes of wetnight in the 1st $(\mathrm{P}<0.001)$, 2nd $(\mathrm{P}=0.001)$, and 3rd $(\mathrm{P}=$ 0.001) months of examinations were significantly different between the control and case groups. The mean of episodes of wet-night, considering age $(\mathrm{P}=0.899)$ and gen$\operatorname{der}(\mathrm{P}=0.607)$ variables, was not significantly different between the control and case groups (Table 3 ). In the current study, HCT caused no complications in the subjects of the case group and no one developed intolerance to HCT. 
Table 1. Age and Gender of the Case and Control Groups ${ }^{\mathrm{a}}$

\begin{tabular}{cccc}
\hline Variables & Case Group & Control Group & P Value $^{\mathbf{b}}$ \\
\hline Age & & & 0.223 \\
\hline 7 & $11(10)$ & $13(11.8)$ & \\
\hline 8 & $14(12.7)$ & $9(8.2)$ & \\
\hline 9 & $5(4.5)$ & $11(10)$ & \\
\hline 10 & $13(11.8)$ & $9(8.2)$ & \\
\hline 11 & $6(5.5)$ & $3(2.7)$ & \\
\hline 12 & $2(1.8)$ & $4(3.6)$ & 0.359 \\
\hline 13 & $5(4.5)$ & $1(0.9)$ & \\
\hline Gender & $1(0.9)$ & $3(2.7)$ & \\
\hline Male & $34(59.7)$ & $27(50.9)$ & \\
\hline Female & $23(40.3)$ & $26(49.1)$ & \\
\hline
\end{tabular}

${ }^{\mathrm{a}}$ Values are expressed as No. (\%).

${ }^{\mathrm{b}} \mathrm{P}$ values $<0.5$ were considered statistically significant.

Table 2. Rate of Wet-night Episodes at the End of Each Month in the Study Groups ${ }^{\mathrm{a}}$

\begin{tabular}{lccc}
\hline \multirow{2}{*}{ Months } & \multicolumn{2}{c}{ Mean Numbers of Wet-Night Episodes } & \multirow{2}{*}{ PValue $^{\mathbf{b}}$} \\
\cline { 2 - 3 } & Case & Control & \\
\hline First & $4 \pm 4.3$ & $7 \pm 7.2$ & $<0.001$ \\
Second & $3 \pm 5$ & $7 \pm 7.6$ & 0.001 \\
\hline Third & $2.7 \pm 5$ & $9.5 \pm 7$ & 0.001 \\
\hline
\end{tabular}

${ }^{\mathrm{a}}$ Values are expressed as mean $\pm \mathrm{SD}$.

${ }^{\mathrm{b}} \mathrm{P}$ value $<0.5$ was considered as the level of significance.

Table 3. Mean Numbers of Wet-night Episodes in the Study Groups Based on Gender and Age ${ }^{\mathrm{a}}$

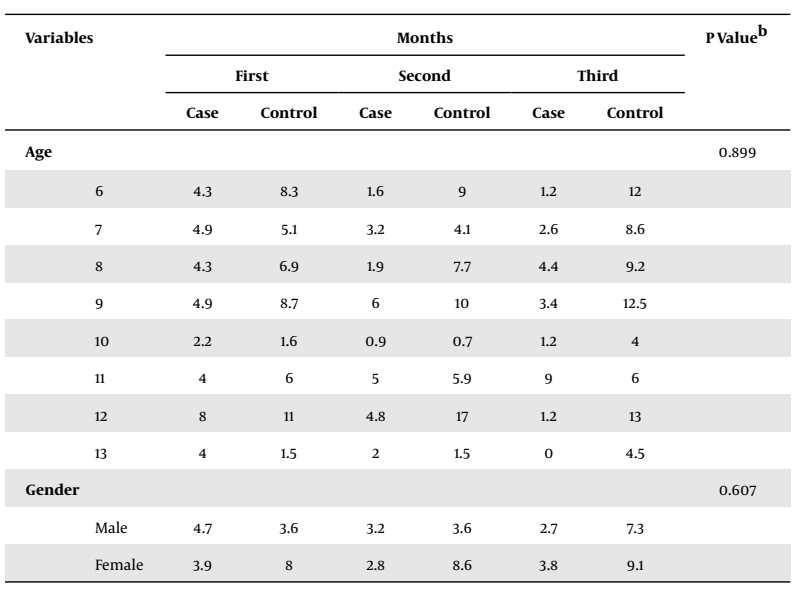

Values are expressed as mean.

$\mathrm{b}_{\mathrm{P} \text { value }}<0.5$ was considered as the level of significance.

\section{Discussion}

In the current study, PMNE improved in the case group who receiving HCT. Alawwa et al. studied the therapeutic effect of HCT on NE. This study was conducted on 40 children with $\mathrm{NE}$ and they used placebo and $1 \mathrm{mg} / \mathrm{kg} /$ day oral HCT; clinical responses of children were studied during a period of 3 months. It was observed that HCT reduced episodes of wet night better than placebo, but both of them were statistically effective on reducing the mean of wet nights; the current study also came to the same conclusion (21). Yousefichaijan et al. in a study on the therapeutic effect of HCT on PMNE only in males, compared the case (HCT and conservative treatment) and control (conservative treatment) groups. They concluded that HCT was an effective therapeutic option; hence, it can be prescribed in the treatment of PMNE (17). Jang et al. in a study showed that the impact of HCT, which induced hypocalciuria in hypercalciuric rats, was associated with increased expression of transient receptor potential vanilloid 5(TRPV5) protein; TRPV5 may also have a significant effect on the regulation of calcium excretion from the urinary system (22). Mechanisms of the relationship between HCT and NE explained by Park et al. (23) confirmed the current study results. Porter et al. reported that due to low cost, ease of use, easy to access, and low side effects of HCT, HCT can be used as an effective drug to treat NE in children (24). In addition, Hoenderop concluded that reabsorption of calcium reduced throughout the down-regulation of TRPV5 that became a factor for calcium loss from urinary system and caused hypercalciuria (25). Raes et al. (15) concluded that there was a correlation between polyuria, hypercalciuria, low urinary osmolality, and increased excretion of sodium in samples, in the urine of night time (15), but these 2 factors were not evaluated in the current study.

However, based on the following reasons, further studies are needed before the administration of HCT as an alternative or adjuvant treatment in NE: 1) Clinical studies on the impact of HCT in NE are few, 2) Laboratory studies on the effect of HCT on the treatment of NE are few and molecular mechanisms are not completely identified, and 3) The effects of different doses of HCT in various forms of NE including primary or secondary with and without monosymptomatic are not found yet. Limitation of the current study was that the 3-month follow-up of children and HCT as a non-routine drug to treat NE may lead to parental noncompliance. In addition, some children and their parents missed follow-up visits during the current study (new patients were replaced). It was explained to the parents that HCT is a cheap and safe drug for their children, in order to increase their cooperation with the study.

Therefore, due to the low number of clinical stud- 
ies and unknown mechanism of this association, we recommend to further studies with larger sample sizes and studies that evaluated different dose of HCT on nocturnal enuresis.

\subsection{Conclusions}

Based on the current study results, improvement of PMNE in children receiving HCT and conservative treatment was significantly more than group that only received conservative treatment.

\section{Footnote}

Conflicts of Interest: The authors declared no conflict of interests.

\section{References}

1. Perrin N, Sayer L, While A. The efficacy of alarm therapy versus desmopressin therapy in the treatment of primary mono-symptomatic nocturnal enuresis: a systematic review. Prim Health Care Res Dev. 2015;16(1):21-31. doi: 10.1017/S146342361300042X. [PubMed: 24252606].

2. Yousefichaijan P, Salehi B, Rafiei M, Ghadimi N, Taherahmadi H, Hashemi SM, et al. Emotional disorders in children with monosymptomatic primary nocturnal enuresis. J Pediatr Nephrol. 2015;3(1):22-5.

3. Ahmed AF, Amin MM, Ali MM, Shalaby EA. Efficacy of an enuresis alarm, desmopressin, and combination therapy in the treatment of saudi children with primary monosymptomatic nocturnal enuresis. Korean J Urol. 2013;54(11):783-90. doi: 10.4111/kju.2013.54.11.783. [PubMed: 24255762].

4. Kiddoo DA. Nocturnal enuresis. CMAJ. 2012;184(8):908-11. doi: 10.1503/cmaj.111652. [PubMed: 22529169].

5. De Bruyne P, De Guchtenaere A, Van Herzeele C, Raes A, Dehoorne $J$, Hoebeke P, et al. Pharmacokinetics of desmopressin administered as tablet and oral lyophilisate formulation in children with monosymptomatic nocturnal enuresis. Eur J Pediatr. 2014;173(2):2238. doi: 10.1007/s00431-013-2108-2. [PubMed: 23989967].

6. Yousefi P, Firouzifar M, Cyrus A. Correlation between sacral ratio and primary enuresis. J Nephropathol. 2012;1(3):183-7. doi: 10.5812/nephropathol.8120. [PubMed: 24475413].

7. Dhondt K, Baert E, Van Herzeele C, Raes A, Groen LA, Hoebeke P, et al. Sleep fragmentation and increased periodic limb movements are more common in children with nocturnal enuresis. Acta Paediatr. 2014;103(6):e268-72. doi: 10.1111/apa.12610. [PubMed: 24612370].

8. Esposito M, Gallai B, Parisi L, Roccella M, Marotta R, Lavano SM, et al. Primary nocturnal enuresis as a risk factor for sleep disorders: an observational questionnaire-based multicenter study. Neuropsychiatr Dis Treat. 2013;9:437-43. doi: 10.2147/NDT.S43673. [PubMed: 23579788].

9. Rezagholi-Zamnjany M, Yousefichaijan P. An overview on peritoneal dialysis. Ann Res Dialysis. 2016;1(1).
10. Lucchini B, Simonetti GD, Ceschi A, Lava SA, Fare PB, Bianchetti MG Severe signs of hyponatremia secondary to desmopressin treatment for enuresis: a systematic review. J Pediatr Urol. 2013;9(6 Pt B):1049-53. doi: 10.1016/j.jpurol.2013.02.012. [PubMed: 23619353].

11. Yousefichaijan P, Rezagholi Zamnjany M, Dorreh F, Rafiei M, Taherahmadi H, Niyakan Z, et al. Comparison of Development Indicators, According to Ages and Stages Questionnaires in Children with Pollakiuria Compared to Healthy Children. Nephro Urol Mon. 2017;In press(In press) doi: 10.5812/numonthly.45898.

12. Yousefi P, Salehi B, Rafeie M, Firouzifar M, Mousavinejad SA. Parents function and behavioral disorders in children with and without diurnal voiding dysfunction: A comparative study. Zahedan J Res Med Sci. 2014;16(9):1-4.

13. Schlomer B, Rodriguez E, Weiss D, Copp H. Parental beliefs about nocturnal enuresis causes, treatments, and the need to seek professional medical care. J Pediatr Urol. 2013;9(6 Pt B):1043-8. doi: 10.1016/j.jpurol.2013.02.013. [PubMed: 23608323].

14. Yousefichaijan P, Rezagholizamenjany M, Rafiei F, Taherahmadi $\mathrm{H}$ Rafiei M. The Relationship between Blood Biomarkers Level and the Prognosis of Nephrotic Syndrome in the Children. Int J Pediatr. 2016;4(9):3489-97.

15. Raes A, Dossche L, Hertegonne N, Nuytemans L, Hoebeke P, Van Laecke E, et al. Hypercalciuria is related to osmolar excretion in children with nocturnal enuresis. J Urol. 2010;183(1):297-301. doi: 10.1016/j.juro.2009.08.175. [PubMed:19914655].

16. Dabrowski E, Kadakia R, Zimmerman D. Diabetes insipidus in infants and children. Best Pract Res Clin Endocrinol Metab. 2016;30(2):317-28. doi: 10.1016/j.beem.2016.02.006. [PubMed: 27156767].

17. Yousefichaijan P, Sharafkhah M, Cyrus A, Rafeie M. Therapeutic Efficacy of Hydrochlorothiazide in Primary Monosymptomatic Nocturnal Enuresis in Boys With Idiopathic Hypercalciuria. Nephrourol Mon. 2015;7(5):e29127. doi: 10.5812/numonthly.29127. [PubMed: 26543832].

18. Deshpande AV, Caldwell PH, Sureshkumar P. Drugs for nocturnal enuresis in children (other than desmopressin and tricyclics). Cochrane Database Syst Rev. 2012;12:CD002238. doi: 10.1002/14651858.CD002238.pub2. [PubMed: 23235587].

19. Butani L. Hydrochlorothiazide reduces urinary calcium excretion in a child with Lowe syndrome. Clin Kidney J. 2015;8(4):459-61. doi: 10.1093/ckj/sfv048. [PubMed: 26251718].

20. Yousefichaijan P, Rafiei M, Aziminejad A, Pakniyat A. The prevalence of hypercalciuria in girl kids with over active bladder.J Renal Inj Prev. 2015;4(4):117-9. doi: 10.12861/jrip.2015.25. [PubMed: 26693498].

21. Alawwa IA, Matani YS, Saleh AA, Al-Ghazo MA. A placebo-controlled trial of the effects of hydrochlorothiazide on nocturnal enuresis. Urol Int. 2010;84(3):319-24. doi: 10.1159/000288236. [PubMed: 20389163].

22. Jang HR, Kim S, Heo NJ, Lee JH, Kim HS, Nielsen S, et al. Effects of thiazide on the expression of TRPV5, calbindin-D28K, and sodium transporters in hypercalciuric rats.J Korean Med Sci. 2009;24 Suppl:S161-9. doi: 10.3346/jkms.2009.24.S1.S161. [PubMed: 19194547].

23. Park SJ, Kim JH, Shin JI. Insight on the mechanism of the effects of hydrochlorothiazide on nocturnal enuresis. Urol Int. 2010;85(2):248. doi: 10.1159/000316105. [PubMed: 20733273].

24. Porter CC, Avner ED. Nelson textbook of pediatrics. Philadelphia: Saunders; 2011

25. Hoenderop JG, van Leeuwen JP, van der Eerden BC, Kersten FF, van der Kemp AW, Merillat AM, et al. Renal Ca2+ wasting, hyperabsorption, and reduced bone thickness in mice lacking TRPV5. J Clin Invest. 2003;112(12):1906-14. doi: 10.1172/JCI19826. [PubMed: 14679186]. 